\title{
Clinical profile and outcome of snake bite in children
}

\author{
Bhusanpatnaik B. ${ }^{1}$, Varma C.D. ${ }^{2}$, Sujatha N.V. ${ }^{3}$, Satyasree T.J. ${ }^{4}$, Sreya A. ${ }^{5}$, V.Priyanka ${ }^{6}$ \\ ${ }^{1}$ Dr. Balaji Bhusanpatnaik, Associate Professor, ${ }^{2}$ Dr. Chandra Deve Varma BSK, Assistant Professor, ${ }^{3}$ Dr. N.V. Sujatha, \\ Junior Resident, ${ }^{4}$ Dr.T. Jogi Satyasree, Junior Resident, ${ }^{5}$ Dr. Sreya. A, Junior Resident, ${ }^{6}$ Dr. V. Priyanka, Junior \\ Resident, all authors are attached with Department of Pediatrics, Maharajah's Institute of Medical Sciences, Nellimarla, \\ Vizianagaram, Andhra Pradesh, India.
}

Corresponding Author: Dr. Balaji Bhusanpatnaik, Associate Professor, Pediatrics, Maharajah's Institute of Medical Sciences, Nellimarla, Vizianagaram, Andhra Pradesh. E-mail: bp198198@gmail.com

\begin{abstract}
Background: Snake bite is generally considered to be a rural problem and has been linked with environmental and occupational condition is a neglected public health problem. This study was conducted to ascertain clinical profile, complication and outcome of snake bite in pediatric population. Methods: Retrospective observational study was done in Paediatrics wards and Paediatric Intensive care unit of tertiary care institute. A medical record files of 200 patients of snakebite, between the periods of January 2013 to August 2018 were recovered from Medical Record and Statistics Section of Institute. Files were analyzed for demographic data; variables included site of bite, time of bite, type of primary treatment and treatment provider, and type of snake poison, common symptoms suggestive of hematotoxicity, myotoxicity and neurotoxicity. Results: Out of total 200 patients, 59.0\% were male and most of snake bites were seen in age group of 6-12 years. All bites were nonprovocative and in 57.5\% lower limb was the commonest site of bite. A $81.5 \%$ patient were primarily treated by medical personnel, $56.5 \%$ patients were received treatment within 1 hour of bite and hospitalized within 6 hours of bite. Cellulitis was commonest complication (39.0\%) followed by vasculotoxicity $(30 \%)$ and neuroparalysis in $(27.5 \%)$, followed by respiratory paralysis in $(19.0 \%)$, coagulation $(17.0 \%)$. Renal replacement therapy was required in $6.5 \%$, blood/blood product transfusion in $11 \%$ patients and case fatality rate was $11.5 \%$. Conclusions: The most vulnerable to snake bites are boys aged more than 5 years. There is an urgent need to spread awareness among the community for avoidance of traditional treatment and any delay in medical intervention in snakebite incidents.
\end{abstract}

Keywords: Neglected public health problem,Snakeenvenomation, Snake bite

\section{Introduction}

Snakebite is one of the neglected tropical diseases that World Health Organization aimed to eradicate [1]. However, it has been excluded from WHO report of 2010 and 2013 on neglected tropical diseases. Currently, snakebite has been included along with other neglected non-tropical diseases such as strongyloidosis, scabies, mycetoma, etc [2,3]. The problem of snakebites has been persistently neglected by public health personnel, clinicians and policy makers even though its social and economic impact are wide spread [4].

Around 4.2 lakh cases of snake bite envenomation and 20,000 deaths have been reported globally, but the actual figures may be higher. Estimation did conservatively have revealed the death rate to be $0.297 /$ lakh

Manuscript received: $25^{\text {th }}$ February 2019

Reviewed: $4^{\text {th }}$ March 2019

Author Corrected: $10^{\text {th }}$ March 2019

Accepted for Publication: $14^{\text {th }}$ March 2019 population ranging from 0.01 in North America region to 2.434 in Oceania region [5]. The regions mostly affected by snake bite are South Asia, South East Asia and sub Saharan Africa [1]. Envenomation in India is estimated to be at $81000 /$ year, which is highest in the year in the world, followed by Srilanka, Vietnam and Brazil [1] In India, Uttar Pradesh, Andhra Pradesh and Bihar are the worst affected states with the majority of deaths being reported in Andhra Pradesh[6].

The increased mortality and morbidity in tropical countries is attributed to scarcity of anti-snake venoms, minimum access and poor quality of health care services [7]. People in countries like India prefer traditional healers rather than trained doctors, mainly because of ignorance and monetary issues as a result of which $77 \%$ of snake bite victims in rural areas die outside the health care setup[8]. Snake bites can cause 


\section{Original Research Article}

severe complications like shock systemic bleeding, respiratory muscles paralysis, acute renal failure and necrosis of tissues at the site of bite. Snakes from the family Viperiadae and elapidaeae known to cause more severe consequences. Since complications of snakebite develop rapidly and irreversibly, medical interventions must be prompt and appropriate [9]. Even though deaths due to snake bite can be prevented, the mortality continues to be high because of lack of knowledge among doctors regarding the management of snake bitecases, this along with delay in conventional treatment, lack of anti snake venom and lack offacilities of tracheal intubation and ventilation by bag-valve mask in neurotoxic cases have been major factors for death due to snake bites [10].

Unlike the other public health problems, which have received a lot of attention from both the policy makers and health care providers, snake bite has been grossly neglected by many. Hence, the current study was conducted with the objective of assessing the clinical and epidemiological profile of snake bite victims admitted to a tertiary care hospitalsin coastal part of South India.

\section{Materials and Methods}

Study design: The series of snake bite cases were studied retrospectively at our tertiary care \& referral hospital that provide care to underprivileged, socioeconomically deprived population.

Study period: the study is conducted over a period of 5 years (January 2013 to August 2018)

Sample size: medical record files of 200 patients were taken statistical section of institute.

Study place: pediatric wards and pediatric Intensive Care Units at Maharajah's institute of medical sciences, Nellimarla, Andhra Pradesh.

Inclusion criteria: Demographic data collected.

The analysed variables included site of bite, time of bite, type of primary treatment and treatment provider, type of snake poison, whether cases had been directly admitted to this hospital or referred from other health centers, time interval between snakebite, common symptoms suggestive of hematotoxicity, myotoxicity and neurotoxicity, local symptoms including fangmarks, condition of wound and initiation of treatment.

Exclusion Criteria: Case where the patients were discharge against medical advised were excluded. Cases of unknown bite in the absence of fang marks or any other symptoms not suggestive of venomous snake bites were also excluded.

Samples collected: Routine and specific investigations were done, these includes complete hemogram, platelet count, peripheral smear, renal function tests, liver function test, urine examination (protein, blood, haemoglobin, myoglobulin), BT, CT. Specific investigation includes serum electrolytes, prothrombin time, activated prothrombin time, and electrocardiogram in some patients.

Ethical Committee Approval: As required by the government of ANDHRA PRADESH, all snake bites are classified as medico-legal cases, whose records were kept separately in medical record section. After retrievening the registration number, the medical records were obtained from the medical case files from the Medical Record Section and Statistical Service of the institute. Information collected to conform to preestablished protocol after approval from institutional ethical committee. We reviewed all the relevant data needed for our analysis.

All patients were treated as per WHO protocol [11]. A detailed systematic and local examination was carried out in all patients. Neostigmine along with atropine was administered to patients with neuroparalysis till reversal of neurotoxic manifestation. Patients were studied for complications at hospital stay. Blood/ Platelet transfusion, ventilatory support and dialysis were carried when indicated. The patients developing severe cellulitis were treated with appropriate antibiotics and anti- inflammatory agents.

Statistical Analysis: The data regarding the numerical variable were summarized thorough average, median and deviation pattern. Comparisons of categorical data were carried out using pearson's chi square or Fischer's exact test were appropriate. $\mathrm{P}$ value less than 0.05 was taken statistically, significant.

\section{Results}

In this series total of 200 patients were registered for the study. Among them, 118 (59\%) were male and $83(41.50 \%)$ females. Most of the bites were seen in children of age group of 6-12 years age group,133patients (66.50\%). Patients were from rural area are130 $(65 \%)$ and $128(68 \%)$ from lower socioeconomic class. In $84 \%$ patients, toilets facilities were available and $49 \%$ were from areas facing problem of night time electric load shedding (Table 1). 
Table 1: Demographic Profile of Snake Bite Patients.

\begin{tabular}{|c|c|c|}
\hline Variables & $\mathbf{N = 2 0 0}$ & Percentage \\
\hline Age in years & 8 & 4.00 \\
\hline $0-1$ & 23 & 11.50 \\
\hline $1-3$ & 38 & 19.00 \\
\hline $3-6$ & 133 & 66.50 \\
\hline $6-12$ & & 59.00 \\
\hline Sex & 118 & 41.50 \\
\hline Male & 83 & 31.50 \\
\hline Female & & 65 \\
\hline Residence & 63 & 1.50 \\
\hline Urban & 130 & 35.00 \\
\hline Rural & & 64.00 \\
\hline Socioeconomic status & 03 & \\
\hline Upper & 70 & 84.00 \\
\hline Middle & 128 & \\
\hline Lower & & 49.00 \\
\hline Toilet facility & 168 & \\
\hline Yes & & \\
\hline Electric load shedding & 98 & \\
\hline Yes & & \\
\hline
\end{tabular}

Most of the snake bite cases were seen during the period of June to September

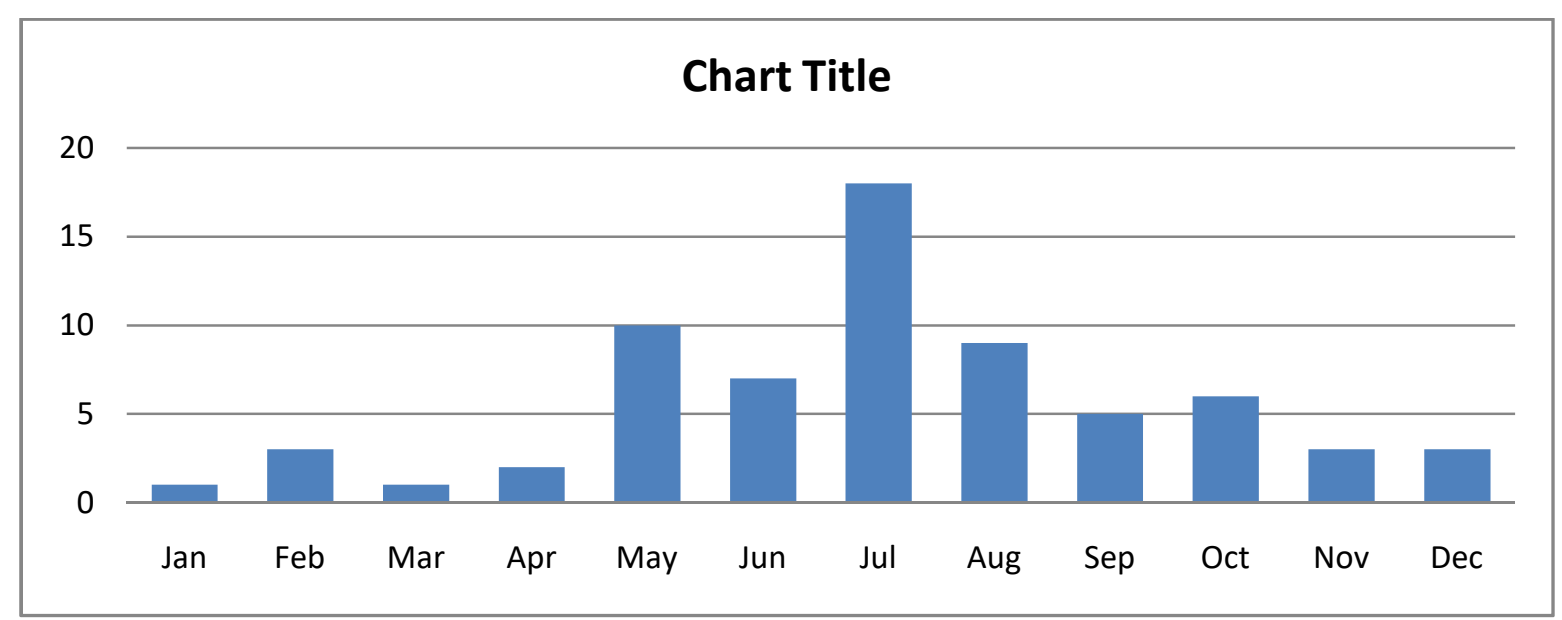

Figure 1: Month wise distribution of Snake bite patients.

All bites were non provocative and in $57.5 \%$ of population in night times. Lower limb 115(57.5\%) was the commonest site of bites followed by upper limb but unusual site like head and trunk was not observed in our study. A $81.5 \%$ patients were primarily treated by medical personnel. $56.5 \%$ patients were received treatment within 1 hour of bite and hospitalized within 6 hours of bite. A 39.0\% patients received Anti snake venom and 90\% tetanus toxoidasa primary treatment.

There was various mode of clinical presentation of patients suggestive of either vasculotoxic or neuroparalytic nature of bite (Table 2). Local edema and cellulitis were observed in $39.0 \%$ patients. Bleeding from local sites, hematuria was present in vasculotoxic bites. Among the neuroparalytic bites, 25 (12.5\%) patients were admitted with altered consciousness. $18(9.0 \%)$ and $13(6.5 \%)$ patients developed diplopia and ptosis in 8 hours of bites respectively and 38 $(19.0 \%)$ patients developed respiratory failures for which ventilatory support was provided. 
Table-2: Clinical profile of Snake bite patients.

\begin{tabular}{|c|c|c|}
\hline Variables & $\begin{array}{l}\text { Patients } \\
(\mathrm{N}=\mathbf{2 0 0})\end{array}$ & Percent \\
\hline \multicolumn{3}{|c|}{ Time of bite } \\
\hline Day & 85 & 42.5 \\
\hline Night & 115 & 57.5 \\
\hline \multicolumn{3}{|c|}{ Site of bite } \\
\hline Upper limb & 85 & 42.5 \\
\hline Lower limb & 115 & 57.5 \\
\hline \multicolumn{3}{|c|}{ Primary Treatment Provider } \\
\hline Medical Person & 163 & 81.5 \\
\hline Paramedical Staff & 38 & 19.0 \\
\hline Quack/Tantric & 8 & 4.0 \\
\hline \multicolumn{3}{|c|}{ Type of primary treatment } \\
\hline Tourniquet applicant & 3 & 1.5 \\
\hline ASV & 78 & 39.0 \\
\hline Tetanus toxoid & 180 & 90.0 \\
\hline Primary treatment $<1 \mathrm{hr}$ of bite & 113 & 56.5 \\
\hline Primary treatment $>1 \mathrm{hr}$ of bite & 88 & 44.0 \\
\hline Admission $<6$ hrs of bite & 130 & 65.0 \\
\hline Admission $>6$ hrs of bite & 70 & 35.0 \\
\hline Local Edema & 78 & 39.0 \\
\hline Pain & 88 & 44.0 \\
\hline Diplopia & 18 & 9.0 \\
\hline Altered consciousness & 25 & 12.5 \\
\hline Ptosis & 13 & 6.5 \\
\hline Respiratory Distress & 38 & 19.0 \\
\hline Local site bleeding & 25 & 12.5 \\
\hline Hematuria & 13 & 6.5 \\
\hline
\end{tabular}

Table-3: Complications of Snake bite envenomation.

\begin{tabular}{|c|c|c|}
\hline Complications & $\mathbf{N = 2 0 0}$ & Percent \\
\hline Vasculotoxicity & 60 & 30.0 \\
\hline Neuroparalysis & 55 & 27.5 \\
\hline Cellulitis & 78 & 39.0 \\
\hline Hypotension & 15 & 7.5 \\
\hline Respiratory paralysis & 38 & 19.0 \\
\hline Acute renal failure & 13 & 6.5 \\
\hline Coagulation & 35 & 17.5 \\
\hline Death & 23 & 11.5 \\
\hline
\end{tabular}

Cellulitis was commonest complication (39.0\%) followed by vasculotoxicity (30\%) and neuroparalysis in (27.5\%), followed by respiratory paralysis in $(19.0 \%)$, coagulation $(17.0 \%)$. Renal replacement therapy was required in $6.5 \%$ (Table 3). In our study, 23 deaths with case fatality reported to hospital more than 6 hours after bite and was primarily treated by Quack and other persons and most of cases died within ten hours of hospitalization

\section{Discussion}

Snake bite is an environmental hazard and lifethreatening emergency associated with significant morbidity and mortality in children. In India, no reliable statistics are available. To remedy the deficiency in reliable snake bite data, it is strongly recommended that snake bites should be made a specific notifiable disease. We bring a result of retrospectively collected data on clinical profile of snake bites in children from central 


\section{Original Research Article}

India. The most vulnerable age group for snake bites includes children over 5 years of age because they are engaged in outdoor games and also older children in rural are as sharing the responsibilities of carrying out outdoor activities like grass cutting, cattle grazing, firewood collection. In this study $66.50 \%$ of the total cases belong to age group 6-12years.

The youngest patient was 9 months old boy bitten at home. Similar types of age distribution were reported by Kumaravel KS et al Chandrasekar C et al, Krishana V Metal [12-16]. Incidence was more in boys (58.75\%) as compared to girls $(41.25 \%)$ this is in accordance with other studies where high incidence is reported in male children which can be attributed to their behavior and nature to playmore outdoor games [17-19].

In our study, 65\% patients were from rural areas and most from lower socioeconomic status. In rural areas, most of the homes do not have toilet facility and recently curtailment of electricity at night as snakes are nocturnally active: incidence of snake bite is more in night times. We observed $57.5 \%$ snake bite in night times and all are no provocative. Most (55\%) of snake bites in our study in month of June to September, as in heavy rain during monsoon, where the holes and burrows occupied by snakes and rats are filled with water and thus the snakes have no shelter. Similar types of observation were reported in previous studies.

Snake bites are usually encountered in the lower limb around the ankle due to accidental stampede while walking or playing in the dark. In this study, 115 $(57.5 \%)$ of cases were bitten on the lower limb, $85(42.5 \%)$ on upper limb. Similar observations are reported in India and world literature but unusual sites like head, trunk was not observed in present study [20]. In rural India, due to mentality of the people to seek treatment from quacks they present to the hospital late after the bite and because of lack of transport facility during night hours the primary center is not approachable. In fact, time of transport and early anti snake venom administration improves the outcome of such patient [21].

In present study, $81.5 \%$ patient were primarily treated by medical personnel, $56.5 \%$ patients received treatment within 1 hour of bite and hospitalized within 6 hours of bite. A 39.0\% patient received anti snake venom and $90 \%$ tetanus toxoid as a primary treatment, death of 23 patients in our study was due to delay in seeking primary treatment, these cases received treatment from unqualified person leading to delay in hospitalization.
Most of the envenomous bites developed local and systemic complication. Vasculotoxic bites resulting into local edema, cellulitis and bleeding from local site were observed in $39 \%$ cases. Coagulation failure (17.5\%), hypotension (7.5\%), acute renal failure $(6.5 \%)$ and these patient required blood/blood product transfusion and renal support. Among neurotoxic bite, pain at local site $(44.0 \%)$ altered consciousness $(12.5 \%)$ and respiratory distress $(19.0 \%)$, ptosis $(6.5 \%)$, diplopia $(9.0 \%)$ were noted. Similar types of complications were reported by Gautam P et al, Adhisivam B et al (22-23). Amongst 23 deaths in present study, 14 were vasculotoxic bite and 9 neurotoxic bite cases. All patients were hospitalized after $6 \mathrm{hrs}$ of bite and received primary treatment from paramedical or quack.

\section{Conclusion}

1.We conclude that the most vulnerable to snake bites are boy aged more than 5 years. Mortalityafter snake bite is preventable if the victim receives timely treatment.

2. Delay in seeking medical aid and ignorance among primary care physicians about the correct treatment of snake bite is also responsible for the morbidity and mortality.

3.Our study concludes that there is an urgent need to spread awareness among the community for avoidance of traditional treatment and to prevent delay in medical intervention in snake bite incidents.

Funding: Nil, Conflict of interest: None initiated, Perission from IRB: Yes

\section{References}

1.World Health Organization. Neglected Tropical Diseases. [Last cited on 2014 Aug07].Available from : http://www.who.int/neglecteddiseases/diseases/snakebi tes/en/

2. Crompton DW, Peters P, editors. World Health Organisaton. Working to overcome the global impact of neglected tropical diseases. Geneva: Department for the Control of Neglected Tropical Diseases, WHO; 2010.p.172.

3. Crompton DW, editors. World Health Organization . Sustaining the drive to overcome the Global impact of neglected tropical diseases; Second WHO report on neglected tropical diseases. Geneva: department for the control of Neglected Tropical Diseases, WHO ; 2013. p.172.

4. Bhaumik S. Snakebite: a forgotten problem. BMJ. 2013 Jan 31;346:f628. doi: 10.1136/bmj.f628. 


\section{Original Research Article}

5. Kasturiratne A, Wickremasinghe AR, de Silva N, et al. The global burden of snakebite: a literature analysis and modelling based on regional estimates of envenoming and deaths. PLoS Med. 2008 Nov 4;5 (11): e218. doi: 10.1371/journal.pmed.0050218.

6. Mohapatra B, Warrell DA, Suraweera W, et al. Snakebite mortality in India: a nationally representative mortality survey. PLoSNegl Trop Dis. 2011 Apr 12;5(4):e1018. doi: 10.1371/journal. pntd. 0001018.

7. Hansdak SG, Lallar KS, Pokharel P, et al. A clinicoepidemiological study of snake bite in Nepal. Trop Doct. 1998 Oct; 28 (4): 223-6. DOI:10.1177/0049475 59802800412

8. Warrell DA, Gutiérrez JM, Calvete JJ, et al. New approaches \& technologies of venomics to meet the challenge of human envenoming by snakebites in India. Indian J Med Res. 2013;138:38-59.

9. World Health Organization. Rabies and Envenoming's: A Neglected Public Health Issue.2007. [Last accessed on 2008 May 01; Last cited on 2014 Jul10]. Available from: http://www.who. int/blood products/ animal_sera/Rabies.pdf.

10. Bawaskar HS, Bawaskar PH. Envenoming by the common krait (Bungarus caeruleus) and Asian cobra (Najanaja): clinical manifestations and their management in a rural setting. Wilderness Environ Med. 2004 Winter;15(4):257-66.

11. Kumaravel KS, Ganesh J. A study on the clinical profile of children with snake envenomation in a tertiary referral centre at Dharmapuri, Tamilnadu, India. Int J Res Med Sci. 2016;4(6):2142-5.

12.Chandrashekar C,Shariff MA, Gopal K, Ravichander B. Clinical profile of snakebite in children. J Evidence Based Medi Healthcare. 2015;2(29):4176-84.

13. Krishana VM, Sheikh NA, Soren C. Clinical profile and outcome of snake bite envenomation in children: a retrospective study in a tertiary care centre KIMS Narketpally. Int J Information Res Rev. 2014;1 (11): 155-8.
14. Sani UM, Jiya NM, Ibitoye PK, Ahmad MM. Presentation and outcome of snake bite among children in Sokoto. North-western Nigeria. Sahel Med J. 2013; 16 (4):148-53.

15. Reddy MP, Sudharshan RC. Clinical, epidemiological and hematological profile of snake bite in children in rural teaching hospital. Int $\mathbf{J}$ Health Sci Res. 2015;5(7):58-63.

16. Lingayat AM, Wankhade PR. Study of clinical profile complications and outcome in patients of snake bite in pediatric age group. Int $\mathrm{J}$ Healthcare Biomed Res. 2015;3(3):203-8.

17. Digra S, Singh V. A clinical profile of neurotoxic snakebite in pediatric population of Jammu region. JK Sci. 2016;18(2):67-70.

18. Chew KS, Khor HW, Ahmad R, Rahman H. A five year retrospective review of snakebite patients admitted to a tertiary university hospital in Malaysia. Int J Emerg Med. 2011;4:41.

19.Wang JD, Tsan YT, Chiao M, Wang LM. Venomous snakebites and antivenom treatment According to a protocol for pediatric patients in Taiwan. $\mathrm{J}$ Venom Anim Toxins Incl Trop Dis. 2009;15(4):667-79.

20. Paudel KM, Poudyl VP, Rayamajhi RB, Budhathoki SS. Clinico-epidemiological profile and outcome of poisonous snake bites in children using the WHO treatment protocol in western Nepal. J Nobel Medical College. 2016;4(7):21-5.

21. Chinchorlikar SV, Patniak B, Raje S. Awareness of snake bite and its first aid management in rural areas of Maharashtra. Indian J Community Health. 2014;26(3): 311-5.

22. Gautam P, Sharma N, Sharma M, et al. Clinical and demographic profile of snake envenomation in Himachal Pradesh, India. Indian Pediatr. 2014 Nov;51 (11): 934-5.

23. Adhisivam B, Mahadevan S. Snakebite envenomation in India: a rural medical emergency. Indian Pediatr. 2006 Jun;43(6):553-4.

\section{How to cite this article?}

Bhusanpatnaik B, Varma C.D, Sujatha N.V, Satyasree T.J, Sreya A, V. Priyanka. Clinical profile and outcome of snake bite in children. Int J Pediatr Res. 2019;6(03):107-112.doi:10.17511/ijpr.2019.i03.01 